\title{
الغزالي والقاعدة الذهبية: أخلاقيات المعاملة بالمثل في أعمال حكيم مسلم 1
}

\author{
ترجمة: د. خالد السباعي 3 \\ بقلم: جاستن باروت \\ كلية الآداب - جامعة مصراتة
}

https://doi.org/10.36602/faj.2018.n12.06

\section{ملخص البحث:}

أصبحت القاعدة الذهبية (عامل الآخرين كما تحب أن يعاملوك) نقطة محورية

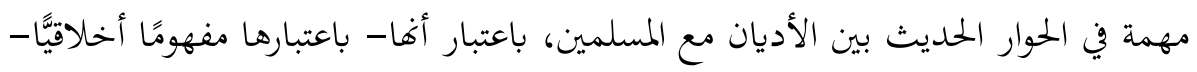

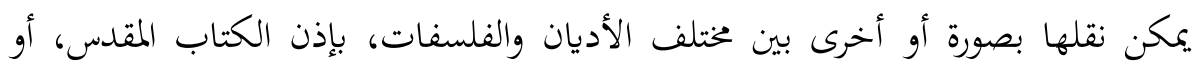

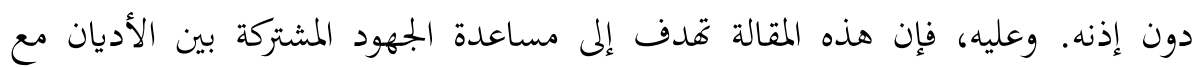
المسلمين من خلال دراسة استخدام القاعدة الذهبية في أعمال الصوفي المسلم، وعالم الأخلاق الكلامي، ${ }^{4}$ علماء الإسلام التقليديين تأثيرًا وشعبية، حيث يُّمس تأثيره وتقديره في الشرق والغرب، لهرب، ضمن الإسلام وخارجه على حلٍّ سواء، وهو يطبق القاعدة الذهبية في صيغٍ مختلفة بوصفها لئهاء

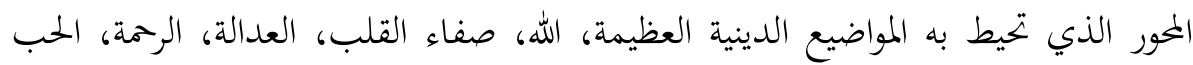

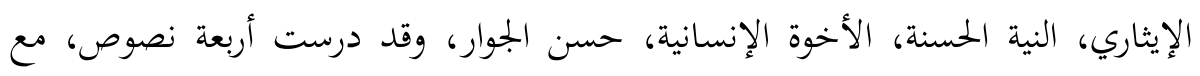
إيلاء اهتمام خاص لعمله الأكثر شهرةً (إحياء علوم الدين).

1 :عنوان البحث الأصلي: Al-Ghazali and the Golden Rule: Ethics of Reciprocity in the

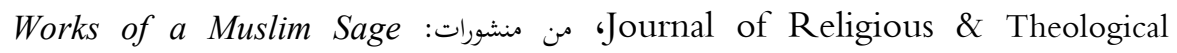
Information, Volume 16, 2017 - Issue 2

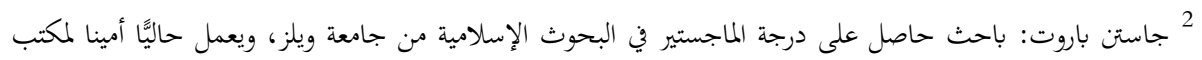

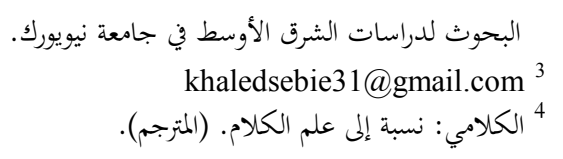




\section{Abstract}

The golden rule (do unto others as you would have them do unto you) has become an important focal point in modern inter- faith dialogue with Muslims. As an ethical concept, it can be transferred, more or less, intact between different religions and philosophies, with or without the authority of scripture. This arti- cle aims to assist interfaith efforts with Muslims by examining the use of the golden rule in the works of 12th century Muslim mys- tic, ethicist, and theologian Abu $\mathrm{Ha}^{-}$mid al-Ghazza ${ }^{-}$i ("Al-Ghazali”). Al-Ghazali is one of the most influential and popular of the clas- sical scholars of Islam, whose impact and appreciation is felt in the East and West, both within Islam and without. He applies the golden rule in various formulations as an axis around which great themes of religion are surrounded: God, purity of heart, justice, compassion, altruistic love, goodwill, human brotherhood, and neighborliness. Four texts are examined with specific attention paid to his most famous work, Ihä́'y'Ulüm al-Dīn.

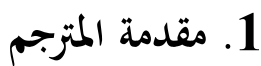

يؤمن الغزالي بأن صلاح المجتمع لا يكون إلا بإصلاح الفرد، وهذا الإيمان مبعثه

إيمانه الراسخ بما تضمنه القرآن الكريم والسنة النبوية المطهرة من توجيهات في هذا الاتحاه، وقد أخذ هذه القضية على عاتقه ووضعها موضع البحث والدراسة مستفيدًا من عمق تجربته الشخصية التي طُوِت بما مرت به من أطوار، تمثلت طورًا في الخوف وأخر في الرجاء وأخيرًا في الزهد، ليخلص بعد ذلك ويقدم كتابه "احياء علوم الدين"، كمرآة تعكس تلك التجربة العميقة المملؤة بالتأملات والانطباعات النفسية التي كان لها بالغ الأثر على كل من تتبعها.

ومن بين المسائل التي رأى الغزالي أغها تُعد محورية في اصلاح الفرد ثم المجتمع "مسألة

المعاملة بالمثل"، لما تقدمه من منطلق أخلاقي للفرد يستطيع من خلاله بحاوز "الأنا" الفردية 
الضيقة، وينفتح من ثم على جميع ما عداه، مقرًا لهم بما يراه له من حقوق وعليهم ما عليه من واجبات، رغم الاختلاف التام عنه والذي قد يكون اجتماعيًا وحتى دينًا يكفل القطيعة بين المرء وغيره، فيرى الغزالي أن التزام أسلوب "المعاملة بالمثل" يُعد محفزًا لمقدرات الذات الباطنية، التي يفضل المرء ظهوره بها أمام غيره، والمتمثلة في العطف والتفاهم المشترك والاحترام، وعليه فإنه وإن كان للمرء من اختلافات قد تقضي على وجوده الايجابي والمثمر اجتماعيًا، فإنه يتضمن في الوقت ذاته سلوك المعاملة بالمثل الذي له أساسه النفسي والذي ما إن التزم به، فإنه سيكفل له الوجود الإيجابي التواصلي المثمر والمرموق.

والواضح أن هذا السلوك (المعاملة بالمثل) لا يكاد يخلو منه توجيه لحكيم ولا وحي لنبي ولا تنظير لمصلح اجتماعي، بحيث إلتقت فيه مختلف الأديان والثقافات والتنظيرات الاجتماعية، وهو ضارب الجذور في القدم بحيث يرده البعض لحكيم الصين "كونفوشيوس"، وفي الإسلام دلت آيات حكيمة في القرآن الكريم عليه، ولعل من أجلى صورها قوله تعالى:

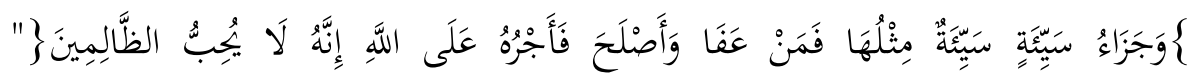

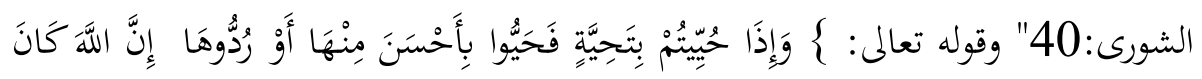
عَلَّن كُلِّ شَيٍٍْ حَسِيبًا \} "النساء:86"، ومن هذا الخطاب القرآين المفتوح انطلق الغزالي في بكثه عن السلوك الأمثل بغية الوصول بالمرء للمثل الأعلى. والباحث "جاستن باروت" والذي عرف عنه شغفه بالفكر الإسلامي، إذ يتناول هذه المسألة عند الغزالي، فإنه لم يدخر جهدًا وهو يتنقل بين مؤلفاته لاستكناه معنى لمفهوم "القاعدة الذهبية" عند الغزالي، وبالفعل استطاع بمقدرته الرائعة الوقوف على ذلك، بحيث يتفق والمنطلق الذي انطلق منه الغزالي، معنى مصبوغ بالصبغة الدينية الصوفية، يهيئ أرضية يتفق الجميع على الوقوف عليها، رغم اختلاف منطلقاقم الدينية والثقافية، ويفتح الباب 
أمام تسامح رحب تشرئب له القلوب، وتنبسط له الجوارح، بالصورة التي أراد لها من خططوا لمبادرة "كلمة سواء" أن تكون، بحيث يُزال اللغط والخلط التي شاع مؤخرًا حول التشكيك في انفتاح الإسلام وسماحته، من أنه لا يحث معتنقيه كما لا يسمح لهم بالتواصل

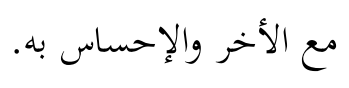

وانطالاقًا من ندرة البحث في هذه المسألة بذاتما كموضوع فلسفي، وكذلك ندرة الأعمال الفلسفية المترجمة عمومًا، كان العمل على ترجمة هذا البحث، باعتباره نصًا فلسفيًا يندرج ضمن فلسفة الأخلاق الإسلامية، وبالرغم أنه كما هو معلوم أن النص المترجم يمكن أن يصاغ بصيغٍ مختلفة، إلا أنه ينبغي عند ترجمة النص الفلسفي خاصًّة الأخذ في الاعتبار المحددات الأسلوبية والتراكيب اللغوية التي تقتضي سياقات معينة تستلزم اجتهادات تأويلية، وهو الأمر الذي يتفق مع مهمة الترجمة ذاهماكوها في فاية المطاف عبارة عن عملية تأويلية، لذلك فإن هذه المهمة من الناحية الفلسفية يُراد من ورائها سبر غور النص لاستنطاق ما هو أبعد مما تبدو عليه النصوص بما هي عليه، على أن ذلك لا يمضي بنا إلى التخلي عن الصيغة التي ظهر بها النص علينا، حتى نتجنب أكبر قدر ممكن من خيانته.

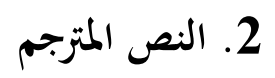

2

إن أخلاقيات المعاملة بالمثل، المعروفة شعبيَّا باسم (القاعدة الذهبية)، هي أي مقولة أخلاقية من شأها تحفيزنا على معاملة الآخرين بالطريقة التي نرغب أن يعاملوننا بها، وتبدو هذه القاعدة في صور وسياقات متنوعة، في ديانات وفلسفات وشعوب مختلفة، يفصلها الزمان والمكان واللغة على نهوٍ واسع، إلى درجة تبدو حكمة عالمية تقريبًا بين البشر (Hertzler,1934,p.418)، فهي أساسية بالنسبة للأخلاق الدينية التوحيدية، وكذلك 
للأخلاق الفلسفية العلمانية، ويمري تسويغها على أساس السلطة الدينية أو العقل أو كليهما، وهي يُعبر بها على حلّّ سواء في الصيغ الإيجابية (عامل الآخرين...)، وصيغ النفي

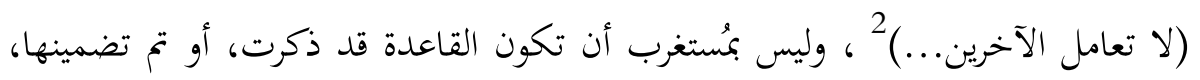
في النصوص الإسلامية الشرعية، وكذلك في كتابات علماء الكلام المسلمين والفلاسفة والصوفيين اللاحقين. (Neusner and Chilton, 2008, p 99). إن الأديان، وفي الواقع الرؤى العالمية بصورةٍ أعم، تتضمن نوعًا من المكِكِّن الذي

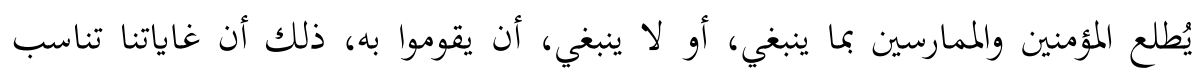

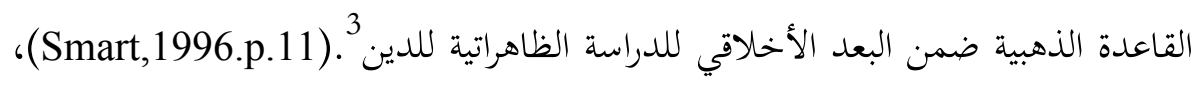

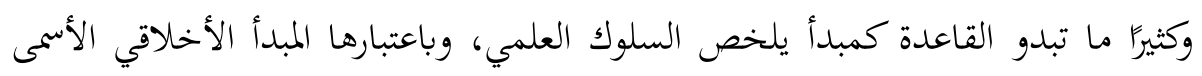

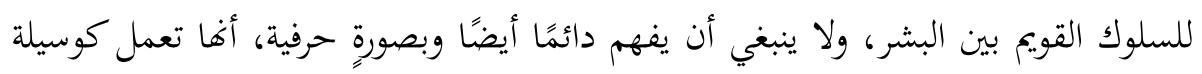

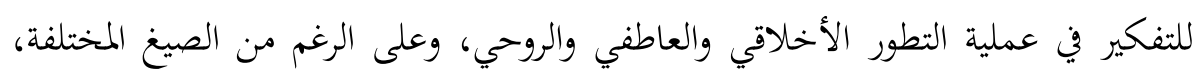

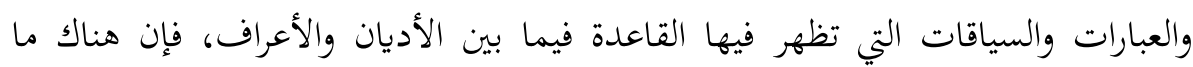
يكفي من الاستمرارية في المعنى والتطبيق لتسويغ وصف أخلاقيات المعاملة بالمثل على أخها

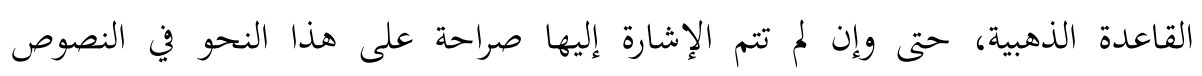
الإسلامية التقليدية، أو غيرها من النصوص الدينية (Wattles,1996, p. 5).

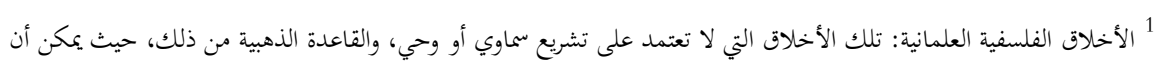

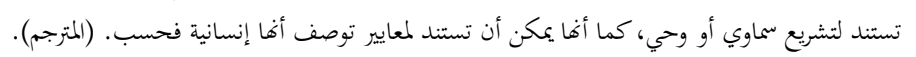

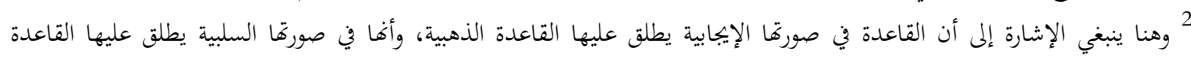

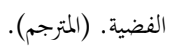
33

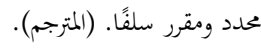


ونظرًا لشبه عالمية القاعدة الذهبية، فقد آن الأوان أن يكون لها دورٌ مهمٌٌمٌ في الحوار الديني المشترك مع المسلمين، ففي أكتوبر من العام (2007م) وقع (138) عالمٍ ومفكرٍ بارٍٍ من المسلمين رسالة مفتوحة، بعنوان (كلمةٌ سواءُ بيننا وبينكم) 1، مؤكدين فيها بأن الإسلام والمسيحية في جوهرهما يشتركان، ويتشاطران الوصايا لمحبة الله، وحب المرء لجاره (Volf, Ghazi, and Yarrington, 2010, p. 3)

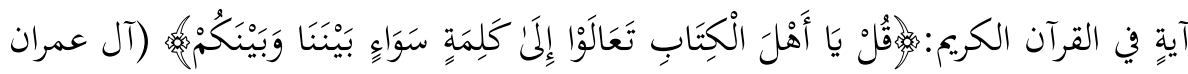
64) (Haleem,2010, p. 59)، وقد وردت ردودٌ ومنشورات من مئات من المفكرين، من خلفيات مسيحية وإسلامية ويهودية، وقد بتحاوزت هذه المحادثات الأولية الدبلوماسية الدينية المهذبة، لتشمل مناقشات مفصلة للتحديات العالمية المتبادلة، مثل: تغير المناخ، وحقوق الإنسان، والتنمية الاقتصادية (11-71-Ansary and Linnan,2010,pp. 7). وفي هذا السياق، فإن فهم وتقدير عمل الحكماء والمتألقين السابقين في التقاليد الدينية العظيمة في العالم يمكن أن يساعدنا على ايجاد أرضية مشتركة أكثر وضوحًا للحاضر، وأحد العلماء المسلمين الذين اعتمدوا اعتمادًا كبيزًا على القاعدة الذهبية، أبو حامد الغزالي (ت.1111)، ويشار إليه فيما يلي باسم الغزالي، أحد أكثر علماء المسلمين الذين شهدقم الدنيا تأثيرًا على الإطلاق، فقد كان فقيهًا، متكلمًا، صوفيًّا، أخلافيَّا، وأفضل ما اشتهر به مواجهته مع الفلاسفة، ونشر رائعته الروحية (إحياء علوم الدين)،

1 مبادرة (كلمة سواء): كانت بدايتها عقب خطاب ألقاه بابا الفاتيكان، ورأى بحموعة من دعاة الإسلام أنه غير لائقِ بالاحترام

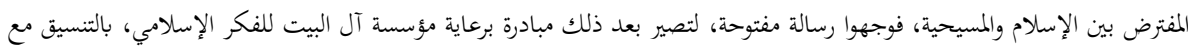

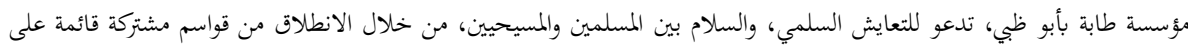

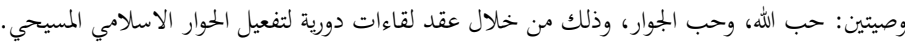


ويشير مؤرخ السنة، وكاتب السير الذاتية الذهبي ${ }^{1}$ (ت.1348م) إلى الغزالي على أنه

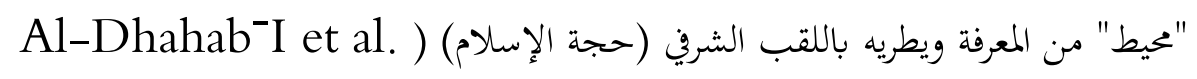

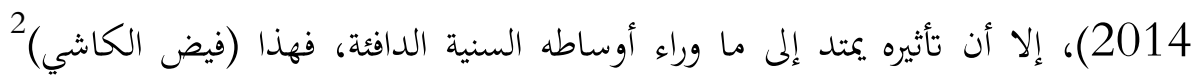

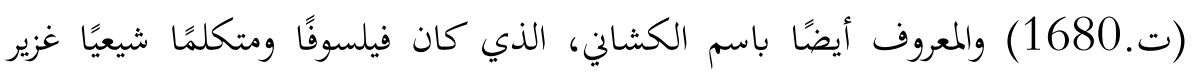
التأليف، والذي كتب (الصافي) عن (الإحياء)، ويقع في عدة مجلدات، لجعل روحانيته

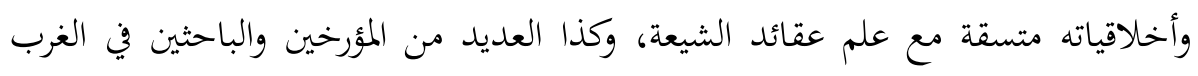
معجبون بإنجازات الغزالي الفكرية: مثل الراحل (وليام مونتجمري وات)، فالغزالي في بعض فئس

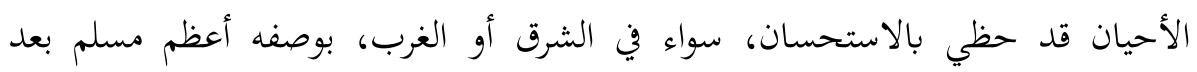
محمد- صلى الله عليه وسلم-، وأنه بأي حال من الأحوال لا يستحق تلك المنزلة (Watt, 1953,p. 14)

ويطبق الغزالي القاعدة الذهبية كمحور مُحاط بالمواضيع الدينية الكبرى، الله، وصفاء القلب، والعدل، والرمة، وحب الإيثار، وحُسن النية، والأخوة الإنسانية، وحُسن الجوار،

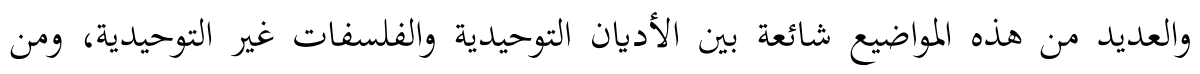
خلال دراستها من حيث استخدام الغزالي القاعدة الذهبية، فإننا نجد الكثير من المواد التي تلهمنا بقدرٍ أكبر من التفاهم المتبادل بين المسلمين وغير المسلمين.

1 شس الدين الذهبي: (1274-1348)، عدث ومؤرخ، وعرف بالكتابة في السير والتراجم، ومن أشهر كتبه "سير أعلام النبلاء".

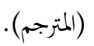

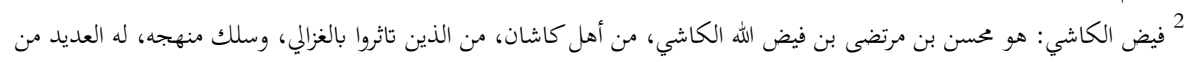

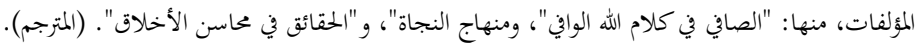




\section{2 الغزالي والقاعدة الذهبية}

إن فلسفة الغزالي الأخلاقية تبدأ بالله، والاعتراف بطبيعة الروح وأصلها وغايتها، وعودةما بعد الموت، ووجهتها النهائية إما السعادة الأبدية، أو السعير في الآخرة ( Abul (Quasem,1975, p.43)، فينبغي أن يكون هدف البشرية موجَّها نحو علاقة متناغمة مع الله، تؤدي إلى جنة الفردوس في الآخرة، فالوسائل ينبغي أن تكون محكمة لتطوير الشخص داخليَّا مقترنة بسلوكيات خارجية من التفاني الورع، والواجب الاجتماعي، وأخلاقه التي محورها الله، ذاته التي فيها للوحي الإلهي الأسبقية، غير أنه لا ينفي تمامًا التفكير الأخلاقي المستقل (Hourani,1985, p. 166).

وفي هذا الإطار، ينظر الغزالي للقاعدة الذهبية على أها مستنتجة بصورة ذهنية من ماهية وجود الله ذاته، وفي أطروحته عن صفات الله، يسرد تسعة وتسعين اسمًا لله، وفقًا لتعداده تعالى، مع إسداء النصح للعابدين للعمل بصورة صحيحة على الآثار المترتبة عن أسماء الله.

الودود: 1 هو اسمُ لله، وَرَدَ في القرآن، وَيُعَبِّر عن محبة الله، ورعايته، ورحمته:

الغفور الودوديهم ( سورة البروج: آية 14) (Haleem,2010, p. 591)، وعلى أنه جزء من طبيعة الله، يفهم الغزالي الحب الإلهي بأنه إرادة الخالق في إعانة خلقه: (الودود: العطوف،

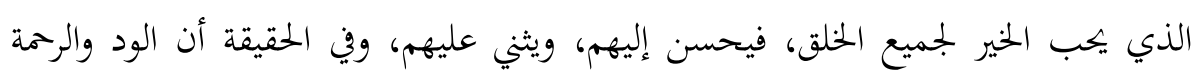

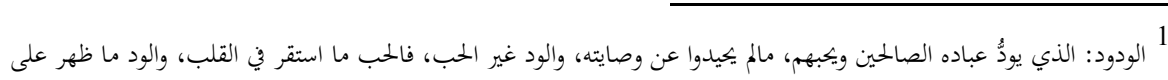

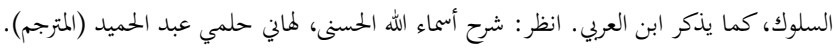


مقصودٌ بمما فقط مصلحة وفائدة أولئك الذين يتلقون الرمة، أو أفم محبوبون)، وأفم لا يجدون علتهما في الرقة أو الميل الطبيعي للودود الواحد.

أما بالنسبة للفائدة الأخرى فهي لباب وروح الرحمة والمودة، وذلك هو المتصور في

حق الله- سبحانه وتعالى-، تلك الصفات غائبة، فيما التجربة تقترن بالرحمة والود، مع ذلك لا تسهم في تحقيق الفائدة التي تقدمها تلك الصفات ( Ninety-Nine Beautiful 119-Names, 118)، فإذا كان الله يريد الخير لجميع خلقه، فمن المنطقي بعد ذلك أن العابد ينبغي عليه أيضًا أن يريد الخير لخلق الله تبعًا للقاعدة الذهبية.

الودود من عباده: من يريد لخلق الله كل ما يريد لنفسه، وأعلى من ذلك من يؤثرهم

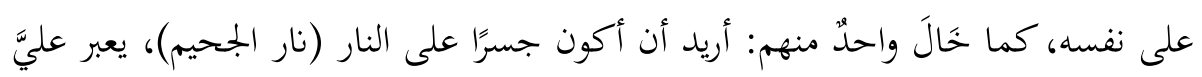
الخلق، ولا يتأذون بها، ${ }^{1}$ وكمال الإيثار والإحسان والغضب والكراهية وما ناله من الأذى. .(Ninety-Nine Beautiful Names, 119)

إن الصياغة الإيجابية للقاعدة الذهبية في هذه الفقرة تستخدم لغة واسعة شاملة؛ حيث ينبغي على المرء أن يريد للمخلوقات (الخلق) ما يريده لنفسه، ويمكن الاستدلال على أن القاعدة تنطبق على غير المسلمين (الكفار) بذلك المعنى الذي ينبغي على المسلم أن يرغب في خلاصهم، فالعابد يجعل نفسه على قدم المساواة مع الآخرين بقدر ما يتعلق الأمر بحسن النية، وأعظم من هذه الفضيلة- على أية حال- هو ممارسة الإيثار، الكلمة التي تحمل تفضيل المرء للآخرين على ذاته نفسها (تقدير الغير على النفس)، ( Altruism 1 قولُ منسوب لأحد الأكابر، وهو من الككام الذي يستلذُ لسماعه، ولا يُعَّل عليه. 
(in World Religions, 74 )،ينغي على المرء أن يرغب في إنقاذ الآخرين من جهنم في الآخرة، لدرجة أنه يتحمل الأذى عنهم في سبيل خيرهم.

إن القاعدة الذهبية المنطقية بالنسبة للغزالي تتضمن تبادلاً خياليَّا للأدوار ، أو أن

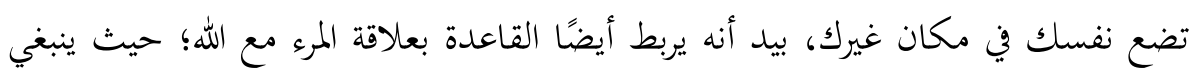

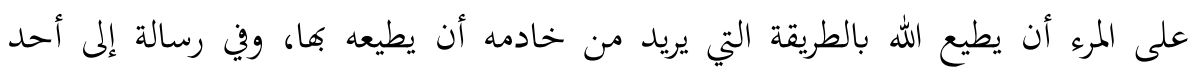

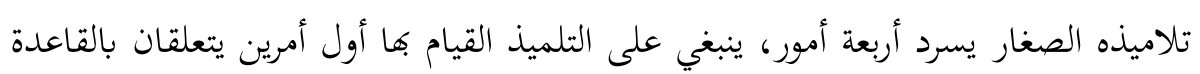

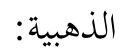

الأول: أن بتعل معاملتك مع الله تعالى، بحيث لو عاملك بما عبدك ترضى، ولا يضيق خاطرك عليه، ولا تغضب، والذي لا ترضى به لنفسك من خادمك المجازى، فلا

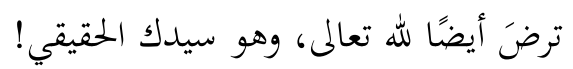

الثاني: كلما عملت بالناس، اجعله كما ترضى لنفسك منهم؛ لأنه لا يكمل إيمان عبد حتى يحب لسائر الناس ما يحب لنفسه. (Letter to a Disciple, 56 ).

وفي هذه الفقرة يمكن للمرء أن يسمع صدى للإعلان الشهير الوارد في إنجيل (لوقا) 10:27"Lucke" عقلك، وجارَك مثل نفسك" (New Oxford Anno- tated Bible, 1851)، وكما ذكر

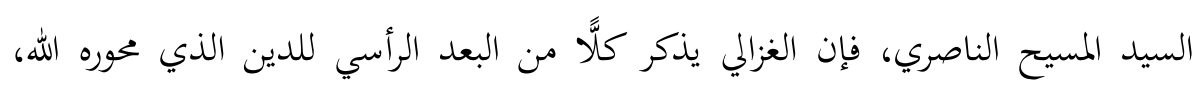

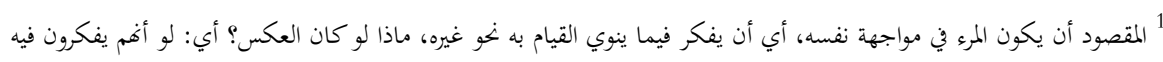

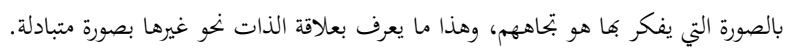


والبعد الأفقي محوره الإنسان، واحدًا تلو الآخر، وهو يستخدم لغة شاملة هنا مرة أخرى، ناصحًا تلميذه بأن يحب لسائر الناس ما يحب لنفسه.

وبما أن الغاية من الحياة بالنسبة للغزالي الفلاح المطلق بالل؛ لذلك فإن الوسيلة المناسبة لهذه الغاية هي تحسين الترتيب الداخلي القويم، وتطهير القلب من الأردان الروحية، وأن الخصال الشخصية الإيجابية، أو (محاسن الأخلاق) الموصوفة في القرآن، هي المعيار الذي يجب على الشخص أن يقيس به صحته الروحية، وعندما يتعلق الأمر بالحديث الشريف، فإن الحديث الأول الذي يُدرجه الغزالي كدليل على حسن الخلق هو قول النبيصلى الله عليه وسلم-: "لا يؤمن احدكم حتى يحب لأخيه ما يحب لنفسه". ( On

.(Disciplining the Soul, 68

إذا كانت القاعدة الذهبية خصلة شخصية إيجابية خيرة، فإنها من تَمَّمككن أن تفهم

أيضًا فيما يتصل بمظاهرها العكسية المتمثلة في صور ورذائل مدمرة، فالحسد- وفقًا للغزالي هو تمني أن يكون فضل الله قد ابتعد عن أولئك الذين قد أُعمم عليهم، وبُوركَ لهم في متعٍ دنيوية، وبعبارة أخرى: هو الرغبة في رؤية الضرر قد جرى عليهم، والخسارة الفادحة قد لحقت بهم، وهو نقيض القاعدة الذهبية، وعلى هذا النحو، ينبغي على العابد أن يطهر قلبه من هذه المشاعر الشريرة، والحسود هو الذي يشق عليه إنعام الله- تعالى - من خزائن قدرته على عبدٍ من عباده، بعلمه، أو مال، أو محبة في قلوب الناس، أو حظٍ من الحظوظ، حتى إنه يحب زوالها عنه، بل لا يصل العبد إلى حقيقة الإيمان ما لا يحب لسائر المسلمين ما يجب لنفسه، بل ينبغي أن يشارك المسلمين في السراء والضراء، فالمسلمون كالبنيان الواحد يشد بعضه بعضًا، وكالجسد الواحد، إذا اشتكى منه عضو اشتكى سائر الجسد. .(Bida ${ }^{-}$yat al-Hida $\overline{-}$ ah, 131) 
وَمَثَلُ مجتمع الإيمان كمثل مبنى أو كيان واحد، يحمل القاعدة الذهبية بعبارات ضمنية، لكن مفهومة؛ بحيث يكون كل فرد في المجتمع هو كجزءٍ من نفسه، وينبغي أن يعامله معاملته لذاته.

وثمة ذنبان آخران من القلب، هما الكبر وعزة النفس، وقد شجبهما لتناقضهما مع القاعدة الذهبية، وفي فقرة بلاغية على نهوٍ خاص، يشجب الغزالي الاعتزاز بالنفس، باعتباره عقبة رئيسية تحرم المسلمين من نيل عدد من الفضائل.

الحقيقة، أن (الكبر) يصير حجابًا دون الجنة؛ لأنه يحول بين العبد وأخلاق المؤمنين كلها، وتلك الأخلاق هي أبواب الجنة، والكبر وعزة النفس يغلق تلك الأبواب كلها؛ لأن المتكبر لا يقدر على أن يحب للمؤمنين ما يحب لنفسه، ولا يقدر على التواضع، وهو رأس أخلاق المتقين، ولا يقدر على ترك الحقد، ولا يقدر أن يدوم على الصدق، ولا يقدر على ترك الغضب، ولا يقدر على كظم الغيظ، ولا يقدر على ترك الحسد، ولا يقدر على النصح Iha 'y'Ulu m al-D .(6: $491-492$

إن صفاء القلب والنفس هو الموضوع في هاتين الفقرتين، بالإضافة إلى أن الربع الثالث، أكبرَ كتب (لإحياء)، يُفَصِّل أساليب التغلب على الرذائل المهلكة وتصصيل الفضائل المنجية، ويناقش الغزالي الأبعاد الداخلية للدين وبحلياقا الخارجية في أقسامٍ منفصلة من أعماله، بيد أنه غالبًا ما يشبك ويربط بينهما، كما لو أهما مواضيع لا يقتصر بعضها على بعض بصورة متبادلة؛ فصفاء القلب ينبغي بالضرورة أن يؤدي إلى الوفاء بالواجبات الدينية والاجتماعية. 
ويطبق الغزالي في عدة أقسام من (الإحياء) على عددٍ من الحالات الاجتماعية، وفي البحث عن المعرفة الروحية والحقيقة، يجد نموذجًا يجتذى به متمثلًا في الإمام الشافعي 1 (ت.820)، الذي يشتهر بتأسيس المدرسة الفقهية التي تحمل اسمه، والتي انضم إليها الغزالي، وكان معروفًا أيضًا بنجاحه في المناقشات التي أُجريت مع علماء المدارس الفكرية الأُخرَ، وسرُّ تحقيق هذا النجاحِ رَوَاه الغزالي؛ وهو كونه يتمثل في نيته الصافية، ووده الطيب تجاه خصومه، قال الشافعي- رضي الله عنه-: "ما ناقشت أحد إلا وتمنيت أن يجري الله الحق على لسانه، وقال: ما كلمت أحدًا قط إلا أحببت أن يوفق ويسدد ويُعان، ويكون عليه رعاية من الله وحفظ، وما كلمت أحدًا قط إلا ولم أبالِ؛ بيَّن الله الحق على لساني أو لسانه" (Iha $a^{-,}{ }^{\prime \prime}$ 'Ulu ${ }^{-} m$ al-D ${ }^{-}$in, 1:99.)

ويعتمد الغزالي على هذه الروح عندما يناقش موانع النقاث المفرط والجدل بين المسلمين، وأحد المزالق من نوع النقاش الذي انتقده هو أنه يُحدث النية السيئة بين الخصوم، والتعارض مع القاعدة الذهبية، ومنها "(شرور الجدل): الفرح لمساءة الناس، والغم لمسارهم، ومن لا يحب لأخيه المسلم ما يحب لنفسه، فهو بعيد من أخلاق المؤمنين، فكل من طلب المباهاة بإظهار الفضل يسره- لا محالة- ما يسوء أقرانه وأشكاله الذين يسامونه في الفضل، ويكون التباغض بينهم كما بين الضرائر" (Iha 'y 'Ulu'm al-D'

1 الشافعي: أبو عبد الله، محمد بن إدريس، الشافعي (767-820ه)، هو ثالث الأئمة الأربعة، وصاحب المذهب الشافعي في الفقه الإسلامي. (المترجم). 
إن نشاط العلماء المتنافسين- من ثم- يُعد ناقصًا روحيًا ما لم يتم في ظل حُسن

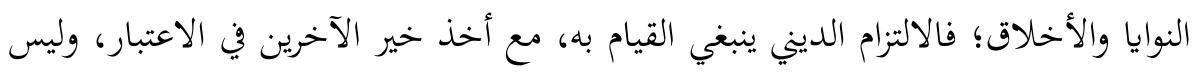
مجرد الرغبة في اثبات صحة موقفنا.

وبعد القيام هذذه المسألة في بداية (الإحياء)، يستشهد الغزالي بالقاعدة الذهبية عدة مرات أُخرَ، عند مناقشة واجبات بتحاه مختلف أعضاء المجتمع، وعندما يتعلق الأمر بالتجارة

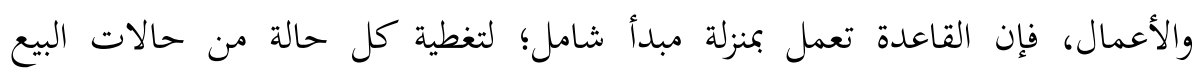
والشراء، وضبطها.

فكل ما يتضرر به المعامل فهو ظلم، وإنما العدل لا يضر بأخيه المسلم، والضابط

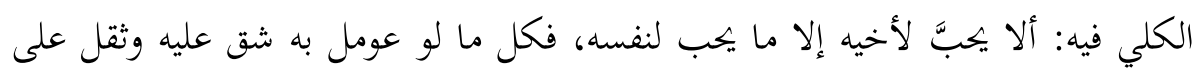
قلبه، فينبغي ألا يعامل غيره به؛ بل ينبغي أن يستوي عنده درهمه ودرهم غيره. قال بعضهم:

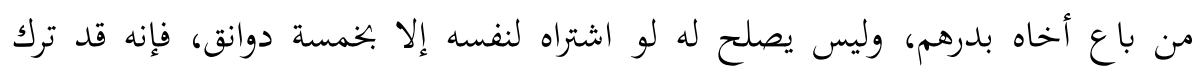

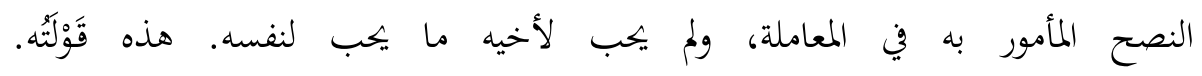
.(Iha ${ }^{-} y^{\prime}{ }^{\prime} U l u^{-} m$ al-D ${ }^{-}$in, 3: 292)

وعلى هذا الأساس يمضي إلى التحريم على التاجر إخفاءً عيوبٍ في قطعة من

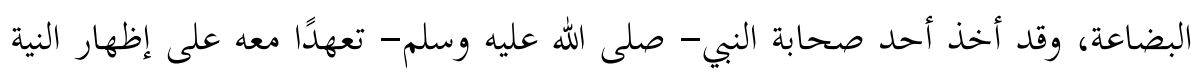

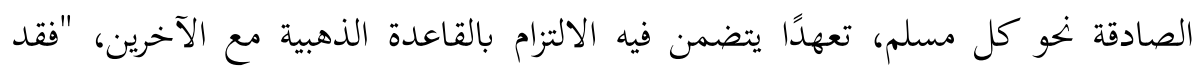

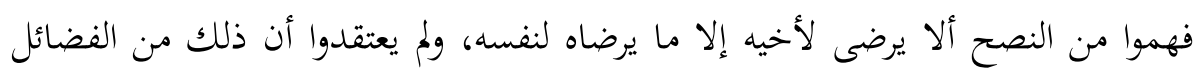

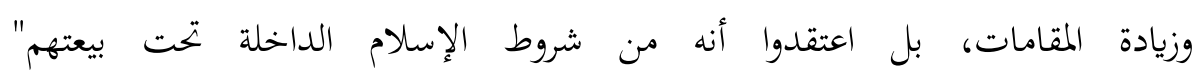
.(Iha ${ }^{-} y^{\prime}{ }^{\prime} U l u^{-} m$ al-D ${ }^{-}$in, 3: 296) 
وينبغي على المعامل أن يكون أكثر اهتمامًا بالحياة الآخرة، وأقل اهتمامًا واهماكًا بشؤون هذه الدنيا، فينصحه الغزالي بأن تكون لديه نية طيبة صافية، وأن يمتنع عن الاستجداء، وأن يكبح جماح طمعه، وأجاز له تَقَصُّدَ إبداء حسن النية إلى المسلمين، وأن يحب لسائر الخلق ما يحب لنفسه، "أجاز له أن يقصد اتباع طريق العدل والإحسان في تعاملاته كما ذكرنا" (Iha ${ }^{-,} y^{\prime} U l{ }^{-} m$ al-D ${ }^{-}$in, 3: 323).

ومرة ثانية يستخدم الغزالي لغة عامة في هذه الصيغة للقاعدة الذهبية، من شأخها أن

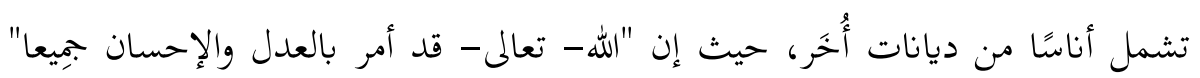
.(Iha ' y'Ulu ${ }^{-} m$ al-D ${ }^{-}$in, 3: 308)

ولدى الغزالي مناقشة مفصلة عن السلوك الحسن والحقوق والواجبات المتعلقة بفئات اجتماعية محددة، وذلك بالمضي أبعد في تناول كتاب (الإحياء) بالدراسة، وتتألف المجموعة الأولى - وهي الأكثر حميمية- من مجموعة الأخوة، والصحبة في سبيل الله، ويسرد لها عشرة أمور واجبات (Abul Quasem,1975, p. 212)، من بينها واجب ستر عيوب الأصحاب، والحفاظ على أسرارهم.

واعلم أنه لا يتم إيمان المرء ما لم يحب لأخيه ما يحب لنفسه، وأقل درجات الأخوة أن يعامل أخاه بما يحب أن يعامله به، ولا شك أنه ينتظر منه ستر العورة، والسكوت على المساوئ والعيوب، ولو ظهر له منه نقيض ما ينتظره، اشْتَدَّ عليه غيظه وغضبه، فما أبعده إذا كان ينتظر منه ما لا يضمره له، ولا يعزم عليه لأجله (hal'y'Ulu'm al-) .(D ${ }^{-}$in, $4: 88-89$

وفي الواقع أن أقل درجة من الأخوة هي تطبيق القاعدة الذهبية بطريقة بتعل من الأصحاب متساوين، ويتمثل جزء من هذه المساواة بين الأصدقاء في صون سمعة بعضهم 
بعضا، والمنافحة عنها ضمن حدود العدالة المعقولة، وعلى أية حال، فإن الحب غير الأناني والإيثاري يعد درجة أخرى أسمى منها.

إن الغيبة، أو التحدث بسوء عن الآخر في غيابه، هو كذلك انتهاكُ للقاعدة

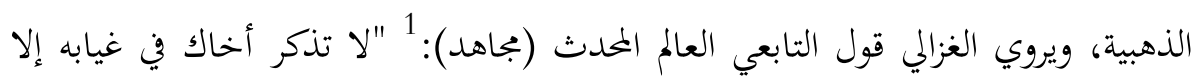
بما تحب أن يذكرك"، ويستشهد بقولٍ آخر لأحد الصالحين غيرِ معروف، وذلك قوله: "ما

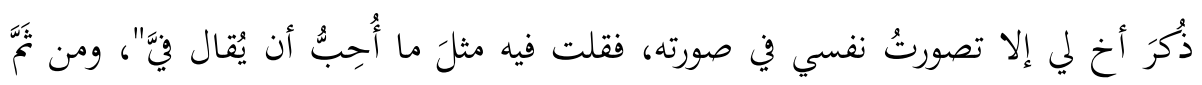
يخلص الغزالي إلى "وهذا هو الإسلام الصحيح؛ وهو ألا يرى لأخيه إلا ما يراه لنفسه" (Iha ${ }^{-,} y^{\prime} U l u^{-} m$ al-D ${ }^{-}$in, 4: 102-03)

وفيما بعدُ من كتاب الإحياء، وبينما يناقش الغزالي الشفاء الروحي للغيبة، يقول: "فإذا كان لا يرضى لنفسه أن يُغتاب، فينبغي أن لا يرضى لغيره ما لا يرضاه لنفسه، وعليه

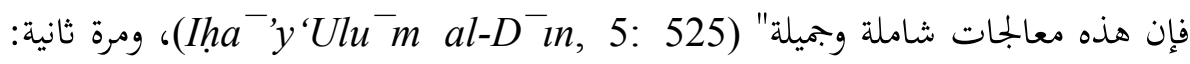
فإن القاعدة الذهبية هي مبدأ شامل للسلوك المستقيم، وفي هذه الحالة تعد دليلا لتجنب العديد من زلات اللسان.

إن التضرع والدعاء لأجل صديق، هو حق آخر للأخوة، متجذر في القاعدة الذهبية: ومن بين حقوقه "أن الدعاء للأخ في حياته وبعد مماته، بكل ما يحب لنفسه ولأهله، فتدعو له كما تدعو لنفسك، فإن دعاءك له دعاء لنفسك على التحقيق". (حقوق الأخوة والصحبة الأحياء)، والسبب في دعاء أحدنا للآخر بالمثل كالدعاء لنفسه هو ديني تمامًا، ويستشهد بقول النبي- صلى الله عليه وسلم: "إذا دعا الرجل لأخيه في ظهر

$$
\text { 1 } 1 \text { بجاهد: مجاهد بن جَبْر (642-722م)، وهو إمام، وفقيه، وعالم ثُقة، ومفسر. (المترجم). }
$$




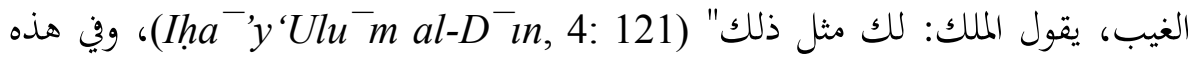
الحال، تكون إحالته إلى القاعدة الذهبية سائغة، من خلال إيمانه بسلوك الملائكة، وليس بأي سبب فلسفي أو عقلاني.

ويناقش الغزالي فروض الصحبة في أطروحة أخرى بعنوان (بداية الهداية)، ويختتم قائمته للفروض مشيرً إلى أغها يمكن تلخيصها جميًا في القاعدة الذهبية: "وعلى الجملة، فيعامله بما يحب أن يُعامَل به؛ فمن لا يحب لأخيه مثل ما يحب لنفسه فأُخَوَتُّهُ نفاق، وهي عليه وبالٌ في الدنيا والآخرة" (al-Bida - yah al-Hida Y-yah, 163 ). وبعد الأخوة والصحبة في سبيل الله تأتي الدائرة الأوسع من المسلمين، وفي كتاب (الإحياء) يعدد الغزالي سبعًة وعشرين من الحقوق، وما يقابلها من واجبات للمسلمين بتحاه بعضهم بعضا (Abul Quasem,1975, p. 214)، ومن بين حقوق المسلم الموجزة في بداية هذا الجزء هي "أن تحب له ما تحبه لنفسك، وأن تكره له ما تكرهه لنفسك"

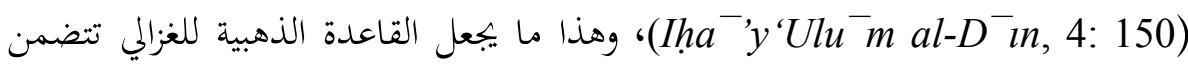
صياغة إيجابية وسلبية على حدٍ سواء، وفي اللغة الفارسية إيجاز لكتاب (كيمياء السعادة)؛ يسرد الغزالي أيضًا هذا باعتباره أول حق للمسلم، على الرغم من أنه يستخدم الصيغة Alchemy of ( السلبية فقط "بأن لا يحب المرء لأخيه المسلم، ما لم يحب لنفسه" (Happiness, 1: 342 والفقرة التالية في (الإحياء) تدعم هذا الحق بالنسبة لمعالجة القاعدة الذهبية، بالإشارة إلى تمثيل النبي- صلى الله عليه وسلم- للمجتمع كبدٍٍ واحد، 1 كيمياء السعادة: أحد مؤلفات الغزالي، كتبه بالفارسية (كيمياي سعادت)، وهو متعلق بالتصوف السنّي، وعلم معرفة النفس، تم النظر

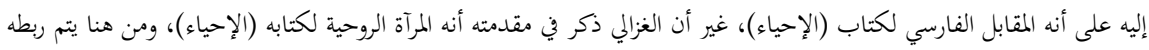

$$
\text { بكتاب الإحياء دومًا. (المترجم). }
$$


"مثل المؤمنين في توادهم وتعاطفهم مثل الجسد، إذا اشتكى منه عضو تداعى له سائر الجسد بالسهر والحمى" (Iha-'y“Ulu'm al-Din, 4:151).

وفي أسفل الحقوق، يذكر الغزالي القاعدة الذهبية مرة أخرى في سياق الإنصاف،

ومن بينها (هذه الحقوق) أن يكون لديه شعورٌ بالإنصاف للناس من نفسه، وأن لا يعاملهم إلا بالطريقة التي يحب أن يعاملونه هما"، وهو يسَوِغ هذا الحق بقول النبي- صلى الله عليه-: "من أسره أن يزحزح عن النار، ويدخل الجنة، فلتأته منيته، وهو يشهد أن لا إله إلا الله،

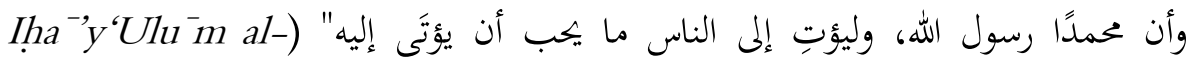
163 حق المسلم في النصيحة الصادقة والنية الحسنة، وما يقابل ذلك من واجب المسلمين

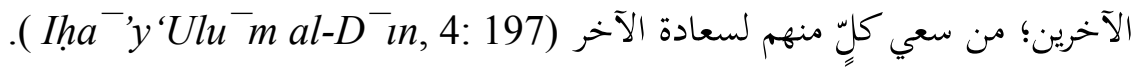
هذا، وآخر وأكبر من بحمع لهم الحقوق هم الجيران، بما في ذلك المسلمون وغير المسلمين، ويقول الغزالي صراحة (الوثني) قد حظيَ بحقوق الجيرة من النبي- صلى الله عليه وسلم-، وهو لا يرى هذه الحقوق كحقوق سلبية فقط، (مثل: تجنب الأذى)، ولكن كحقوق إيجابية أيضًا، "واعلم أنه ليس حق الجوار كف الأذى فقط، بل احتمال الأذى... ولا يكفي احتمال الأذى، بل لا بد من الرفق، وإسداء الخير والمعروف"

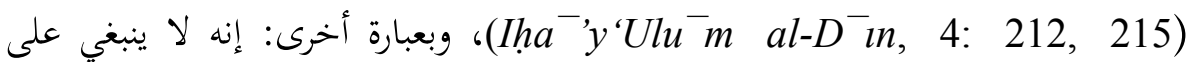
المسلم أن يتجنب مجرد الظلم، بل إن من واجبه أيضًا تقديمً المعاملة الكريمة الاستباقية للجيران.

ولكي يوضح الغزالي هذه النقطة، يروي قصة الكاتب الفارسي الشهير الذي اعتنق الإسلام (عبد الله المقفع) (ت 757): "بلغ ابنَ المقفع أن جارًا له يبيع داره في دين رَكِبهُ، 
وكان يجلس في ظِل داره، فقال: ما قمت إذن بحرمة ظل داره، إنْ باعها معدَمًا، وهكذا دفع (ابن المقفع) إليه ثمن الدار، وقال: لا تبعها. وقد شكا أحدهم كثرة الفئران في داره، فقيل له: لو اقتنيت هرًّا، فقال: أخشى أن تسمع الفئران صوت الهر، فتهرب إلى دور الجيران، فأكون بذلك قد أحببت لمم ما لا أحب لنفسي" ) .(4: $215-16$

ويبدي ابن المقفع شغفًا غريبًا برفاه جيرانه، وهذا الشغف مقامُ على افتراض القاعدة الذهبية، إلى حد تحمل الأذى في سبيلهم، ويتسنى لنا أن نفهم من هذه الفقرة بأن القاعدة الذهبية بالنسبة إلى الغزالي تنطبق على سائر الجيران بغض النظر عن معتقداقم الدينية. ومع ذلك، فإن نقاش القاعدة الذهبية يصبح أكثر تعقيدًا عندما يكون هناك عاملان أخلاقيان، أو أكثر، أو أولويات أخلاقية في حال معينة، فيقرّ الغزالي بحقائق الحرب، وحتمية التصدي للظلم، والدفاع عن الأبرياء، وينكر الإحسان إلى "كل أولئك الذين يعصون الله بمعصية التعدي على الآخرين، أو بعبارة أخرى: أولئك الذين ينتهكون

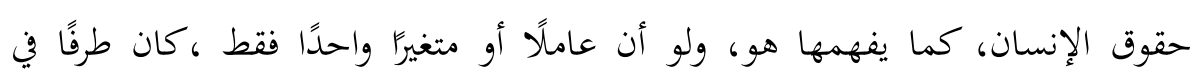
معادلة "تسوية" أخلاقية، فإن القاعدة الذهبية تنطبق حتى على أولئك الذين يضطهدون، أو يسببون أذى شخصيًا، وعلى أية حال، إذا كانت متغيرات متعددة متضمنة في المعادلة الأخلاقية، فإن الغزالي يُرجئ معاملة القاعدة الذهبية إلى المرء الذي انتهكت حقوقه: "والعفو عن من ظلم، والإحسان إلى من أساء من أخلاق الصديقين، وإنما يحسن الإحسان إلى من أساء من ظلمك، فأما من ظلم غيرك وعصى الله به، فلا يحسن الإحسان إليه؛ لأن في الإحسان إلى الظالم إساءةً إلى المظلوم، وحق المظلوم أولى بالمراعاة، وتقوية قلبه بالإعراض 
عن الظالم أحب إلى الله من تقوية قلب الظالم، فأما إذا كنت أنت المظلوم فالأحسن في

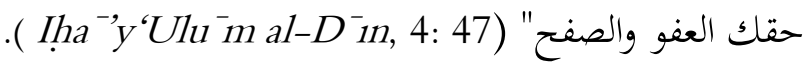

وليس بالضرورة أن تكون القاعدة الذهبية مَنْقُوضةً في وصف الغزالي لكي يبدي

العداء في سبيل الله نحو الظالم، فنية هذا العداء ليست إرضاءً للانتقام من أجل الانتقام في حد ذاته، كما يناقش في مكان آخر أنه ينبغي أن يكون دافع المرء بالكلية هو التقرب لله من خلال الطاعة، "من كان غرضه محض التقرب إلى الله تعالى فهو مخلص" (Al-Ghazali (on Intention, 58 )، بل إنه يرى الوضع من خلال تسلسل الحقوق، وحاجة المظلومين لاسترداد حقوقهم، قبل أن تبدوَ الرأفة إلى الظالم، والدافع الكامن وراء العداء في سبيل الله ينبغي أن يكون خالصًا نحو هذه الغاية.

ولهذا السبب يوجِّه الغزالي قُُّرَاءه للنظر بعينٍ ثاقبة لنواياهم كلما اعتقدوا أن اظهار العداء في سبيل الله مناسبٌ؛ فالعداء ينبغي أن يكون بدافع الاهتمام بالحقوق ومصلحة المظلومين، وصالح المجتمع ككل طبعًا لما يريده الله، فالعداء في الله الذي يدفعه الحسد والغرور والعجرفة أو الحقد البغيض- وجميعها أبغضها الله- تعد غير شرعية، ومن ناحية أخرى، فإن الرحة والرفق يمكن أن يكونا مذمومين إذا صدرا عن نيةٍ سيئة، وأديا إلى عواقب وخيمة؛ إذ في الرفق والنظر بعين الرحمة إلى الخلق نوع من التواضع، ويف العنف والإعراض نوع من الزجر، والمستفتَى فيه القلب، فما يراه أَمْيَلَ إلى هواه، ومقتضى طبعه، فالأولى لئل ضده؛ إذ قد يكون استخفافه وعنفه عن كبر، وعُجْب، والتذاذ بإظهار العلو، والإدلال بالصلاح، وقد يكون رفقه عن مُداهنة، واستمالة قلب؛ للوصول به إلى غرض، أو الخوف من تأثير وحشته، ونفرته في جاه أو مال، بظنٍ قريب أو بعيد، وكل ذلك مردد عن إشارات

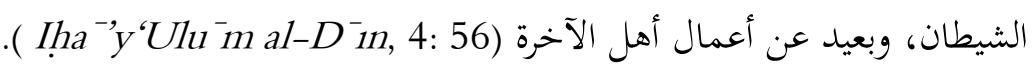


وهذه الفقرات تسلط الضوء على صعوبة استدلال القاعدة الذهبية من حيث علاقتها بأوضاع العداء العادل والعقاب الشرعي، ومع ذلك فإن القاعدة ذاتا لم تلغَ بهذه الحقائق الدنيوية القاسية، بوضوح تُقَسِّم أولئك الذين يستحقوها أكثر، سواء فرد مظلوم أم مجتمع بشكلٍ عام، فالحكمة والاستبطان (التفكير النفسي الدقيق) مستلزمان للعمل ضمن المعضلة الأخلاقية المعقدة التي لا تتسنى أجوبة سهلة لما، فأفكار الحكماء هي ذاتية بالضرورة، وليست دائمًا دارجة بالمعنى الشرعي، الأمر الذي يجعل استدلال القاعدة الذهبية في هذه الحالات أقل شأنًا من العلم الفلسفي، وأكثر من الظن الروحي العالي. 3.

إن أخلاقيات الغزالي الدينية الصارمة تدعمها القاعدة الذهبية، التي غالبًا ما يوظفها كمبدأ موجز للتوجيه الأخلاقي في سياقات متنوعة، وهو يربط القاعدة بعدد من الموضوعات الأخلاقية الأُخرَ البارزة في الأدب الإسلامي التقليدي (القديم) والحديث، وهي الموضوعات ذاتا التي تحدث في كثير من التقاليد الدينية والفلسفية الأخَر، ولعل أهم العلاقات بين الأديان مع المسلمين هو تطبيقه الواضح بصورة أو أخرى للقاعدة الذهبية على المسالمين من غير المسلمين، على رغم الظروف المؤسفة للعداء وبجابهة الظلم، والمساواة الضمنية في أخلاقيات القاعدة الذهبية لدى الغزالي تعني أساسًا دينيًا ضمن الإسلام التقليدي القديم؛ من أجل فهم مشترك لحقوق الإنسان الأساسية الحديثة، والتعاون بين الأديان بشأن مجابهة الصعوبات العالمية المتبادلة، مثل: تغير المناخ، والتنمية الاقتصادية العادلة، وتقدير قاعدة الغزالي الذهبية قد يساعد أيضًا غير المسلمين على التعاطف بشكلٍ أفضل مع مواطنيهم المسلمين، ومن الممكن أن يقلل العداء الشعبي نحو الإسلام، الذي هو نتاج تضليل الإنترنت، والخطاب السياسي الانفعالي المحموم. 


\section{قائمة المراجع}

Abul Quasem, Muhammad (1975). The Ethics of al-Ghazali: A Composite Ethics in Islam. Petaling Jaya: Quasem.

Coogan, Michael D., Marc Z. Brettler, Carol A. Newsom, and Pheme Perkins. The New Oxford Annotated Bible: With the Apocrypha. New York: Oxford University Press, 2010.

Al-Dhahab ${ }^{-}$, Muhammad A., and Shu'ayb Arn ${ }^{-}$a'- uț;, et al (2014). Siyar A'l- am al-Nubal ${ }^{-}{ }^{\prime}$ '. Dimashq: al-Ris ${ }^{-}$alah al-" ${ }^{-}$almiyah,.

Al-Ghazz ${ }^{-} \mathrm{al}^{-}$, and Anthony Shaker. Al-Ghazali on Intention, Sincerity and Truthfulness: [Kit ${ }^{-}$ab al-Niyya wal'l-Ikhl- as wa'l Sidq] Book XXXVII of the Revival of the Religious Studies [Ihy ${ }^{-}{ }^{\prime}$ ' 'Ul' $u m$ al- $D^{-}$in]. Cambridge, UK: Islamic Texts Society, 2013.

Al-Ghazz ${ }^{-}{ }^{-}{ }^{-}$, Jay R. Crook, and Laleh Bakhtiar. The Alchemy of Happiness (Kimiya al-Saadat). Chicago, IL: Great Books of the IslamicWorld, 2008.

Al-Ghazz ${ }^{-}{ }^{-}{ }^{-}$, and 'Abd H. M. Darw ${ }^{-}$1sh. Bid ayat al-Hid ayah. Bayr ${ }^{-}$ut: $\mathrm{D}^{-}$ar Ș ${ }^{-}$adir, 1998.

Al-Ghazz ${ }^{-}{ }^{-}{ }^{-}$, andW.M.Watt. The Faith and Practice of AlGhaz ${ }^{-} a{ }^{-}{ }^{-}$. London: G. Allen and Unwin, 1953.

Al-Ghazz ${ }^{-} \mathrm{al}^{-}$1, and 'Abd -Q. S. 'Aydar ${ }^{-}$us. Ihy ${ }^{-}{ }^{-}$' ' $U l^{-}$um al-D' ${ }^{-}$in. Jiddah: $\mathrm{D}^{-}$ar al-Minh ${ }^{-}$aj lil-Nashr wa-al-Tawz ${ }^{-}$', 2011.

Al-Ghazz ${ }^{-}{ }^{-}{ }^{-1}$, and Tobias Mayer. Letter to a Disciple: Ayyuh ${ }^{-}{ }^{\prime} l-$ Walad. Cambridge, UK: Islamic Texts Society, 2005.

Al-Ghazz ${ }^{-}$al $^{-}$, David B. Burrell, and Nazih Daher. The Ninety-Nine Beautiful Names of God: Al- Maqsad al-Asn ${ }^{-} a f$ $S \_h \_a r h A_{s m}^{-}{ }^{-}$'All ${ }^{-}$ah al-Husn ${ }^{-} a$;.Cambridge, UK: Islamic Texts Society, 2011. 
Al-Ghazz ${ }^{-}{ }^{-}{ }^{-}$, and TimothyWinter. On Disciplining the Soul [Kit ${ }^{-}$ab Riy - adat al-Nafs], \&On Breaking the Two Desires [Kit- ab Kasr al-S_h_ahwatayn]: Books XXII and XXIII of the Revival of the

Religious Sciences [Ihy ${ }^{-}{ }^{\prime}$ ' 'Ul ${ }^{-}$um al- $D^{-}$in]. Cambridge, UK: Islamic Texts Society, 1995.

El-Ansary, Waleed \& Linnan, David (2010). Muslim and Christian Understanding: Theory and Application of "a CommonWord." New York: Palgrave Macmillan.

Haleem, M. (2010). The Qur'an: English Translation with Parallel Arabic Text. Oxford: Oxford University Press.

Hertzler, J. O. (1934). On Golden Rules. The International Journal of Ethics. 44.(4) 418-36.

Hourani, George (1985). Reason and Tradition in Islamic Ethics. Cambridge: Cambridge University Press, 1985.

Al-K' ${ }^{-}{ }^{-}{ }^{-}$, Fayḍ M. M., and 'Al- ${ }^{-}$A. Ghaff ${ }^{-}{ }^{-}$1;. Al-Mahajjah alBayd ${ }^{-}{ }^{\prime}{ }^{-}{ }^{-}$Tahdh $^{-} \mathrm{l} b$ al-Ihy ${ }^{-} a$ '. Tihr ${ }^{-}$an: Maktabat al-S. ad ${ }^{-} \mathrm{uq}$, 1939.

Neusner, Jacob \& Chilton, Bruce (2005). Altruism in World Religions. Washington, D.C.: Georgetown University Press.

Neusner, Jacob \& Chilton , Bruce, (2008). The Golden Rule: The Ethics of Reciprocity in World Religions. London: Continuum.

Smart, Ninian (1996) . Dimensions of the Sacred: An Anatomy of theWorld's Beliefs. Berkeley: University of California Press.

Volf, M; Ghazi, M., and Yarrington, M (2010). A CommonWord:Muslims and Christians on Loving God and Neighbor. Grand Rapids:W. B. Eerdmans Pub. Co.

Wattles, Jeffrey (1996). The Golden Rule. New York: Oxford University Press. 